\title{
Narrative review of intrathecal drug delivery (IDD): indications, devices and potential complications
}

\author{
Michele Antonio Capozza, Silvia Triarico, Stefano Mastrangelo, Giorgio Attinà, Palma Maurizi, \\ Antonio Ruggiero
}

Unità di Oncologia Pediatrica, Fondazione Policlinico Universitario A. Gemelli IRCCS, Università Cattolica Sacro Cuore, Rome, Italy

Contributions: (I) Conception and design: MA Capozza, S Triarico, P Maurizi; (II) Administrative support: A Ruggiero; (III) Provision of study materials or patients: S Mastrangelo, G Attinà; (IV) Collection and assembly of data: MA Capozza; (V) Data analysis and interpretation: S Triarico, MA Capozza; (VI) Manuscript writing: All authors; (VII) Final approval of manuscript: All authors.

Correspondence to: Palma Maurizi, MD. Unità di Oncologia Pediatrica, Fondazione Policlinico Universitario A. Gemelli IRCCS, Università Cattolica Sacro Cuore, Largo A. Gemelli, 8, 00168 Rome, Italy. Email: palma.maurizi@unicatt.it.

\begin{abstract}
The management of chronic refractory pain (non-neoplastic and cancer-related pain) remains a therapeutic challenge. The continuous intrathecal (IT) administration of drugs may play an important role in the possible management options. Intrathecal drug delivery devices (IDDDs) may be effective for patients with refractory chronic pain. Therefore, they may be adopted for non-oncologic pain in patients with compression fractures, spondylolisthesis, spondylosis, back surgery failure syndrome and spinal stenosis. Oncologic patients can benefit from these treatments in a variable way according to tumor characteristics, prognosis, periprocedural imaging and risk of disease progression. In this review, we describe the most commonly used drugs (opioids and non-opioids), their pharmacokinetic and pharmacodynamic features and indications of use. The most used drugs are morphine, hydromorphone, fentanyl, methadone, bupivacaine, clonidine, and ketamine. Patient evaluation before the device implantation should be based on clinical examination, medical records assessment and psychometric evaluation. The infusion pumps available on the market are both non-programmable (with continuous IT deliver of drugs) and programmable (with variable deliver of drugs according to their flow rate). Moreover, we describe the procedure of implantation and the potential complications of IT drug delivery (such as bleeding, infection, loss of cerebrospinal fluid, wound seroma, loss of catheter pump propellant).
\end{abstract}

Keywords: Intrathecal drug delivery devices (IDDDs); chronic pain; opioids; complications, surgical implant

Submitted May 09, 2020. Accepted for publication Jul 31, 2020.

doi: 10.21037/atm-20-3814

View this article at: http://dx.doi.org/10.21037/atm-20-3814

\section{Introduction}

\section{Background}

Chronic pain conditions that affect many patients with malignant and non-malignant diseases have a negative impact on their quality of life (QoL). The definition of "refractory" pain includes therapy failure to achieve treatment results (i.e., inadequate pain relief, no improvement of daily functioning or intolerable adverse effects), despite pain associated psychiatric disorders and psychosocial factors have been evaluated. Intrathecal drug delivery devices (IDDDs) may be considered in treatment strategies available for the management of pain in patients with refractory chronic pain (1).

Age, symptoms and disease of oncologic patients are the variables that can help to choose the most appropriate neuromodulation technique. Moreover, before starting a trial with IDDDs, it is important to consider specific diagnoses, through physical examination, assessment of patients' comorbidities and psychosocial evaluation (2).

It has been considered that if high doses of systemic opioids have been administered prior to initiate intrathecal 
Page 2 of 10

Table 1 Disease indications for IDD (modified by PACC) (2)

Axial neck or back pain (not a surgical candidate)
Multiple compression fractures
Discogenic pain
Spinal stenosis
Diffuse multiple-level spondylosis
Failed back surgery syndrome
Abdominal/pelvic pain
Visceral
Somatic
Extremity pain
Radicular pain
Joint pain
Complex regional pain syndrome
Trunk pain
Postherpetic neuralgia
Post-thoracotomy syndromes
Cancer pain, direct invasion and chemotherapy-related

Analgesic efficacy with systemic opioid delivery complicated by intolerable side effects

IDD, intrathecal drug delivery; PACC, Polyanalgesic Consensus Conference.

(IT) therapies, the latter can result in reduced activity. For this reason, before starting IT drugs it is recommended to wean or reduce systemic opioids dosage (3).

\section{Objectives}

In this review, we describe the most commonly used drugs for intrathecal drug delivery (IDD), their pharmacokinetic and pharmacodynamic features and indications of use. Moreover, we describe the procedure of surgical implantation and the potential complications of IT drug delivery.

We present the following article in accordance with the Narrative Review reporting checklist (available at http:// dx.doi.org/10.21037/atm-20-3814).

\section{Methods}

A narrative overview of the literature has been performed,

\section{Capozza et al. IDD: a promising strategy for refractory chronic pain}

synthesizing the findings of literature from 1986 to today, retrieved from searches of computerized databases.

\section{Indications for IDDs}

Spinal cord stimulation and IDD are recommended for moderate or severe trunk and limb pain and if other antalgic therapies have failed. Table 1 outlines different diseases for which IDD is indicated (3).

Duarte $e t a l$. in their study monitored for an average of 13 years 20 patients with chronic non-malignant pain treated with IT drugs (4) and they noted a statistically significant improvement for sensory and psychosocial variables. Selected patients with chronic non-malignant pain may benefit from long-term analgesic management with IT therapy. These conditions can include spondylolisthesis, spondylosis, back surgery failure syndrome, spinal stenosis and compression fractures (5).

However, Hayes et al. (6) stressed the lack of a clear benefit from IT therapy, which seems to offer a moderate pain relief advantage in the first 6 months after implantation, with benefit decreased over time and a documented reduced patients' overall functional capacity. For these reasons, IT administration was discontinued in 25 patients, switching to oral or transdermal administration. Transient symptoms of abstinence, increased pain and reduced physical activity were observed when treatment was discontinued. However, patients improved significantly after the discontinuation of the opioid infusion, with a reduction in sweating, weight gain, edema and abdominal discomfort. Moreover, there was a decrease of visits to the pain unit for the follow-up treatment. Based on this experience and on randomized studies about the use of IT infusion in patients with chronic non-malignant pain, the discontinuation of established IT therapy in patients with chronic non-malignant pain seems to be an appropriate management option $(7,8)$.

Concerning chronic malignant pain, more than $33 \%$ of patients with metastatic or advanced-stage cancer have moderate to severe pain; moreover, in approximately 10 $30 \%$ of patients with limited life expectancy, an adequate pain relief still is not achieved. IDD allows a valid pain relief with fewer side effects in patients who have not responded to a combination of systemic analgesic treatments. Before implanting an IDDD in oncologic patients several factors have to be evaluated, such as tumor characteristics, prognosis, periprocedural imaging and the risk of disease progression (8).

Stage of disease and life expectancy will determine the 
Table 2 Dose (range) for IT bolus trailing as recommended by $\operatorname{PACC}(2)$

\begin{tabular}{ll}
\hline Drug & $\begin{array}{l}\text { Recommended dose (maximum for naïve } \\
\text { patients }\end{array}$ \\
\hline Morphine & $0.1-0.5 \mathrm{mg}(0.15 \mathrm{mg})$ \\
Hydromorphone & $0.025-0.1 \mathrm{mg}(0.04 \mathrm{mg})$ \\
Fentanyl & $15-75 \mu \mathrm{g}(25 \mu \mathrm{g})$ \\
Sufentanil & $5-20 \mu \mathrm{g}$ \\
Bupivacaine & $0.5-2.5 \mu \mathrm{g}$ \\
Clonidine & $5-20 \mu \mathrm{g}$ \\
Ziconotide & $1-5 \mu \mathrm{g}$ \\
\hline
\end{tabular}

*, starting doses of medication in the opioid-naïve patient for outpatient bolus delivery do not exceed $0.15 \mathrm{mg}$ morphine, $0.04 \mathrm{mg}$ hydromorphone, or $25 \mu \mathrm{g}$ fentanyl.

implementation of IDDDs and the selection of drugs. If patient life expectancy is less than 3 months IDDDs are not implanted. Patients with intractable pain due to advanced malignant tumors may benefit from long-term reduction of analgesia, receiving fewer side effects and a better QoL from opioid-sparing. In their study, Carvajal et al. demonstrated that IT is very effective and safe in the long-term management of malignant refractory pancreatic cancer pain. The rate of complications was low although the study included a fragile population with an advanced stage of disease. In patients managed with IDDDs, they found a better QoL, with reduced side effects (9).

Depression and other mental disorders in patients with chronic pain are commonly encountered (10), but on the other hand it has been described that IT therapy has poor long-term results when personality disorders are present (11). Thus, to define which patients are suitable to receive an implantable neuromodulation system, it is necessary first to evaluate their psychological profile, through a multidimensional assessment of pain in its sensory, emotional and cognitive components. Furthermore, it is necessary to assess adherence to the proposed treatment (12).

Nevertheless, according to the Polyanalgesic Consensus Conference (PACC) guidelines, psychological evaluation is not necessary for oncologic patients with pain.

The evaluation of patients applying for implantation of the neuromodulation system should follow three basic criteria: the clinical interview, the review of medical records and the psychometric evaluation. It is recommended to start with the lowest possible IT dose defined as the trailing dose, which leads to a pain reduction of between $30 \%$ and $70 \%$ (usually about $50 \%$ ). Then to proceed slowly towards an upward titration of the drug guided by the analgesic response and the presence of side effects. Table 2 shows the doses recommended by PACC for IT bolus trailing (2).

The blood-brain barrier (BBB) represents the major obstacle to the administration of drugs into the central nervous system (CNS), delaying the passage of $98 \%$ of systemically administered drugs into the cerebrospinal fluid (CSF) (13).

IT injection of therapeutic molecules allows to by-pass the $\mathrm{BBB}$, allowing the same analgesic activity of systemic administration, but using lower dosages of drugs, with fewer systemic side effects. In fact, drugs that target the CNS but are not free to pass BBB, result more effective when administered intrathecally, as they are free to spread through the pious arachnoid and the white substance of the spinal cord. The dorsal horn (in particular the lamina II of the gelatinous substantia) represents the anatomical region where the receptor sites of most drugs administered (except baclofen and local anesthetics) are located intrathecally to obtain pain relief (14).

Concerning the chemical characteristics of the various compounds administered by IT, hydrophilic drugs have a longer half-life that leads them to penetrate deeper into the spinal cord with a more rostral diffusion. On the other hand, lipophilic drugs have a limited diffusion, allowing greater precision when they are administered at a specific point (15).

\section{IT drugs used for IDD}

Food and Drug Administration (FDA) and European Medicines Agency (EMA) approve currently only ziconotide and morphine for IT infusion for pain management. However, different monotherapies or combined agents, including hydromorphone, fentanyl, sufentanil, bupivacaine, and clonidine are used in clinical practice, as off-label. The main pharmacodynamic characteristics of IT drugs are illustrated below in Table 3 (1).

Morphine is the widest drug adopted as first-line therapy. $\mathrm{He}$ is a mu-opioid agonist. Recent long-term studies support the effectiveness of IT morphine in the treatment of patients with chronic pain (2). Preclinical evaluation in many animal models demonstrated that morphine could lead to the formation of space-occupying masses or IT granulomas $(16,17)$.

Hydromorphone is a mu-opioid agonist (18). It is used 
Table 3 Recommended starting dosage ranges, maximum concentrations and daily doses of IT agents as recommended by PACC (2)

\begin{tabular}{llll}
\hline Drug & Starting dose for long term therapy* & Maximum concentration & Maximum dose per day \\
\hline Opioids & & & \\
Morphine & $0.1-0.5 \mathrm{mg} /$ day & $20 \mathrm{mg} / \mathrm{mL}$ & $15 \mathrm{mg}$ \\
Hydromorphone & $0.01-0.15 \mathrm{mg} /$ day & $15 \mathrm{mg} / \mathrm{mL}$ & $10 \mathrm{mg}$ \\
Fentanyl & $0.5-1.2 \mu \mathrm{g} /$ day & $10 \mathrm{mg} / \mathrm{mL}$ & $1 \mathrm{mg}$ \\
Sufentanil & $25-75 \mu \mathrm{g} /$ day & $5 \mathrm{mg} / \mathrm{mL}$ & $0.5 \mathrm{mg}$ \\
Anesthetics & & $30 \mathrm{mg} / \mathrm{mL}$ & $15-20 \mathrm{mg}^{+}$ \\
Bupivacaine & $0.01-4 \mathrm{mg} /$ day & $1,000 \mu \mathrm{g} / \mathrm{mL}$ & $600 \mu \mathrm{gg}$ \\
Clonidine & $20-100 \mu \mathrm{g} /$ day & $100 \mu \mathrm{g} / \mathrm{mL}$ & $19.2 \mu \mathrm{mg}$ \\
Ziconotide & $10-20 \mu \mathrm{g} /$ day & & \\
\hline
\end{tabular}

*, starting doses of continuous IDD should be half of the trial dose for opioid based medications; ${ }^{+}$, maybe exceeded in end of life care and complicated cases as determined by medical necessity. IT, intrathecal; IDD, intrathecal drug delivery; PACC, Polyanalgesic Consensus Conference.

in first or second-line treatment, with a higher cost than morphine. Preclinical studies in large animal models have shown that when administered via IT it can lead to the formation of granulomas at high concentrations $(19,20)$.

Fentanyl is a lipophilic agonist of opiates mu, used as first-line treatment for localized pain, due to its good profile during prolonged infusions. Preclinical studies of fentanyl or alfentanil infusion in large animal models have shown that granulomas are not an encountered side effect even at high drug concentrations $(21,22)$.

Sufentanil is a potent mu-opioid agonist, but there are no important recent studies that considers the use of sufentanil in IT infusion (23).

Methadone is a racemic compound, with N-methylD-aspartate (NMDA) receptor antagonist activity on the D-isomer and mu opioid agonist activity on the L-isomer (17). Because all compounds with NMDA activity have severe neurotoxic effects, there are concerns about methadone IT infusion (24). The continuous infusion of isomers has caused spinal toxicity and granulomas in animal models. In a prospective study, 13 of 24 patients, previously treated with multiple IT drugs without benefits, experienced improved pain control with IT methadone, with improved QoL and no side effects (25).

Ziconotide blocks type $\mathrm{N}$ presynaptic calcium channels in the dorsal horn of the spinal cord (26,27). Patients with neuropathic pain refractory to systemic pre-trialing opioid therapy may benefit from the use of ziconotide. Other advantages of using this drug via IT include the absence of respiratory depression and the possibility of using low dosages for analgesia (28). Ziconotide should be the first choice in IT therapy if there are no psychiatric changes or kidney disease. However, ziconotide is difficult to manage, especially at higher doses, because of a narrow therapeutic window and requires careful and targeted dosage. Moreover, severe side effects can be reduced by starting with low doses of ziconotide followed by slow titration (29). Rapid titration is associated with cognitive and neuropsychiatric alterations (psychosis, suicide). Adverse effects on CNS include ataxia, nystagmus, nausea, dysmetria, agitation, dizziness, hallucinations and coma. The sudden interruption does not cause withdrawal or rebound effects. Few cases of rhabdomyolysis caused by administration of IT ziconotide are described, although an increase in serum creatine kinase has been reported in up to $40 \%$ of patients $(30,31)$.

Bupivacaine is an amide commonly used as a local anesthetic in spinal anesthesia and also in IT administration as off-label drug (32). Hydromorphone and bupivacaine are efficacious for therapy of chronic pain of back surgery failure syndrome. Hayek et al. in their retrospective analysis demonstrated that these drugs allow a better reduction of pain intensity than oral opioids (33). Since bupivacaine has raised lipid solubility, it also has a limited IT spread. For this reason, it is necessary to insert the IT catheter in the posterior space at pain level (34). If high doses of bupivacaine reach the bloodstream severe cardiotoxic may occur, but potential sensorimotor loss is the limiting effect of bupivacaine infusions (35). If continuous infusions are used rather than boluses, the onset of adverse effects can be reduced. Doses of bupivacaine greater than $15 \mathrm{mg} /$ day 
may lead to clinically relevant side effects, such as urinary retention, weakness, fatigue, drowsiness and paresthesia (36).

Clonidine is an alpha 2 adrenergic agonist; it has an anti-inflammatory effect by inhibiting glial cell activation and the activation of the NF- $\mathrm{kB}$ and $\mathrm{p} 38$ (MAP kinases), which lead to the reduction of pro-inflammatory cytokines. These cytokines are release by activated glial cells of the spinal cord and contribute to the increasing painful conditions. In several clinical studies, clonidine resulted effective for improving analgesia and enhancing the effects of opioids $(37,38)$. However, clonidine may cause important cardiovascular side effects, peripheral edema and sedation in a dose-dependent manner. It may determine hypotension at low doses and hypertension at high doses, with potential life-threatening hypertensive crises and stress-induced cardiomyopathy.

Ketamine inhibits the spinal NMDA receptors, increasing the pain control capacity of morphine at the spinal level (39). Racemic ketamine, a non-competitive NMDA receptor antagonist, as well as its active $S$ (+)-ketamine enantiomer, has been claimed for IT and epidural use in the treatment of major untreatable pain that doesn't respond to increased opioid doses (40). Concerning the potential neurotoxicity of ketamine, histopathological alterations in the spinal cord have been seen after long-term IT ketamine treatment (41). In a cancer patient treated with $5 \mathrm{mg} /$ day of IT ketamine for 3 weeks, subpial vacuolar myelopathy was found postmortem (42).

\section{Complications of IDDDs}

For chronic severe pain therapy IT infusion of opioids is an established practice, whose side effects are now well known (43). Bleeding can occur due to ineffective hemostasis, use of anticoagulants, vascular lesions and secondary bleeding. Bleeding with hematomas formation at the insertion of the pump may cause swelling, pressure and pain. This complication requires a rapid intervention (2). Pocket hematoma should be treated aggressively by reducing dead space as much as possible and ensuring good hemostasis before the pocket site is closed. Bleeding in the deep spinal or epidural space, although extremely rare, correlates with increased neurological morbidity. The use of fluoroscopy can reduce periosteal damage or spinal/epidural trauma. Important hemorrhage in the epidural space may produce an epidural hematoma, with consequent spinal cord compression and paraplegia, increasing back pain and neurological deficits. Hustak et al. reported on a patient with a subarachnoid hemorrhage who needed surgical removal of epidural patch placed for post-dural sting headache (PDPH) (44).

Infections are avoidable using appropriate antibiotics and intensive monitoring (45). Factors that increase the chance of developing an infection at the surgical site are malnutrition, obesity, smoking, anemia, cancer, diabetes mellitus, cardiovascular disease and the use of alcohol. Surgeons recommend the use of intraoperative antibiotic irrigation (46) and the regular evaluation of the implant site if pain, erythema, tenderness, swelling, drainage, fever and leukocytosis are present; patients should also stop smoking about 2 months before this elective surgery. If superficial infections are present, microbiological samples must be taken and antibiotic therapy started, to try to avoid the removal of the implant. When the infection involves the pocket or the catheter or develops into the epidural or IT spaces, the device should be immediately removed and intravenous antibiotics administered. IT infections are infrequent and occur with fever, nuchal rigidity and hyperleukocytosis. If infection is suspected CSF should be sent for microbiological samples (47).

Urgent computed tomography (CT) or magnetic resonance imaging (MRI) may better define the presence of epidural abscess, for planning neurosurgical or spinal surgery and prevent serious neurological complications.

Loss of CSF may occur due to incorrect connection or to leakage from the catheter; sustained loss of CSF may cause PDPH and its sequelae. Therefore, catheter abnormalities must be excluded if severe PDPH symptoms are present; in particular, these complications should be considered when CSF cannot be aspirated from the pump port or when it is present around the pump itself. The presence of pericatheter CSF can be dealt with conservatively augmenting intake of fluids, or with common analgesics, caffeine, and rest. In case of significant symptoms, epidural patch, surgical closure of the dural damage, replacement of the catheter and sutures on the dura mater near the catheter may be required. Major losses may produce a collection of subcutaneous CSF close to the dorsal incision defined as hygroma (pseudomeningocele), that will require surgery in most of the cases (48).

Wound seroma surrounding the pump pocket or in the spine has been reported at the catheter insertion. Posterior wound seroma may develop if there is a loss of CSF, while pump pocket seroma may be formed in subjects with low albumin levels or with venous or lymphatic obstruction. The latter type of seroma could persist up to 2 months, but 
is self-limiting or only require an abdominal binding agent. In seromas with local painful complications, a drain and an abdominal binder could be used. In case of suspected infection, microbiological analysis of CSF must be performed and systemic antibiotic treatment must be started. If this approach fails, the pump should be removed (49).

Possible mechanic complications are a loss of catheter pump propellant (detected as an abnormal rate of drug delivery leading to overdose or underdose with acute withdrawal symptoms), mechanical problems of the pump, loss of the administered agent, catheter displacement, twisting of the catheter (50). Only personnel trained to accurately assess pain and perform physical examinations should take care of medication administration. Asepsis should be maintained during each refill. Drug concentrations and combinations should be used according to guidelines (2). The most frequent drug-related side effects include hypersensitivity or allergy that can often be reduced or eliminated by slowing the drug administration or by drug titration (45).

IT opioids can lead to respiratory (51), itching, nausea, vomiting (52), increased sweat, edema of the lower limbs, weight gain, urinary retention (53), sedation, constipation, alteration of memory or mood and headaches. Withdrawal syndrome can develop after sudden interruption of opioid infusion occurs (54).

Alterations of the hypothalamic-gonadal axis and of the hypothalamic-adrenal axis due to chronic use of IT opioids result in hypogonadism and hypotestosteronism with impaired sexual function, decreased libido, infertility and osteoporosis. Management options may include stopping or reducing the opioid treatment, changing to a different opioid drug or starting the hormonal supplementation (55).

Sterile inflammatory masses called granulomas may form near the tip of the IT catheter, thus, a prompt diagnosis is mandatory. The exact etiology is unknown, but they are probably caused by a reaction to the catheter tip or to the opioid infusion, or by a mild local infection. These granulomas form between the spinal cord and dura mater, occurring mainly in the thoracic area causing compression of the spinal cord. This leads to an alteration of motor and sensory functions, to the onset of root pain in the thoracic or lumbar regions and reduced analgesia $(56,57)$.

MRI remains the gold standard to rule out the presence of an inflammatory mass caused by the catheter, although CT-myelogram with the infusion of contrast medium through the pump offers a cheaper technique (58). An incorrect diagnosis could lead to permanent neurological lesions.

To prevent granulomas, the administration of the lowest effective drug dose and concentration is recommended (59).

Treatment of IT granuloma is based on the patient's conditions. In the absence of neurological deficits, the infusion medication should be switched to sterile normal saline (60). A monthly MRI is recommended for monitoring mass regression. After symptom recovery, it is possible to restart a non-opioid drug administration, performing an MRI every 3 months. In case of neurological changes, surgery and removal of the IT catheter are indicated (61).

Spontaneous intracranial hypotension (SIH) and headache may occur after implantation (62). Loss of CSF at the connection point between the catheter and the intradural space is an infrequent complication and could present initially as an occipital, hammering headache that worsens in the upright position and during exertion. MRI is the standard instrument to confirm these anomalies, showing alterations of subarachnoid reservoir and intracerebral ventricles dimensions, thickening of the cranial meninges, modifications in pituitary gland size and alterations of the spinal cord (63).

\section{Type of IDDDs}

IT administration of drugs requires the placement of an infusion pump that includes a drug reservoir, a mechanical pump and a catheter implanted in the IT space. In addition to a wide variety of catheter systems, there are both nonprogrammable and programmable pumps on the market. A non-programmable fixed flow pump provides a continuous volume of drug in the IT space, maintaining constant flow and ensuring fixed daily drug delivery. Although these systems are less expensive, any dose change requires a change in the concentration of the drug in the reservoir. On the other hand, the flow rate of the drug can be regulated by a programmable pump that deliver different doses. Complex dose changes can be preselected by the medical staff, in order to administer bolus doses as requested by the patient, through external wireless transponders (64).

The two most frequently used variable flow pumps on the market are the continuous peristaltic pump and the valve bolus pump. SynchroMed ${ }^{\circledR}$ II Pump (Medtronic Inc., Minneapolis, MN, USA) is a peristaltic pump, which consists of a system of roller rotors and gears that introduces agents from the reservoir through an internal catheter, in a peristaltic sequence (65). Since the system uses gases under pressure, the administration of drugs depends on ambient 
variables, such as high altitudes, hyperbaric chambers or scuba diving (64). Prometra ${ }^{\circledR}$ IDDS (Flowonix Medical Inc., Mount Olive, NJ, USA) is a valve pump that includes a positive pressure system through two microvalves (inlet and outlet), a dosing chamber and a flow activated valve. Drug delivery is obtained by positive pressure that pushes the drug through the opening inlet to the dosing chamber. Moreover, it can deliver a precise dosage, without dosage fluctuations caused by external factors such as pressure and temperature variations (66).

\section{The surgical implant of IDDDs}

The IDDD is usually placed in the abdominal wall, using a tunneled catheter in the subcutaneous tissue of the sacrum, between the costal margin and the iliac crest. Pre-surgical marking is usually performed in accordance with the patient for obtaining a comfortable position, usually above the waistline (66).

In the operating room, the patient is placed on the bed on his flank with the side of the reservoir facing up. The procedure starts by positioning a Tuohy needle towards the sacrum and moving it forward in a paramedian plane until a perforation of the dura mater is obtained. The stylet is then removed and the CSF flows through the needle. Afterwards a catheter is inserted into the subarachnoid space. With the Tuohy needle in place, the surgeon cuts caudally to the needle site and passes into the skin and subcutaneous tissues, determining a deep dissection up to the supraspinous ligament. A non-absorbable suture is placed to the supraspinous ligament and the Tuohy needle is taken out, with the catheter still in position. Then the catheter is anchored to the supraspinous ligament. The free flow of CSF inside the catheter system is checked after it has been fixed. Following, the reservoir pocket is formed with a cut that continues along the previously marked site on the abdominal wall. A subcutaneous pocket one inch deep is created using the blunt caudal dissection at the incision. The pump reservoir is placed and fixed to the deeper layer of the pocket preventing it from rotating or tilting. Moreover, both IT catheter and pump are attached through a dorsal tunnel to the ventral pump reservoir. Finally, each incision is sutured in sequence and the device is activated and programmed for dispensing the medication (67).

\section{Conclusions}

The administration of medications by the IT route appears to be a good way to treat chronic intractable pain usually poorly controlled by systemic medical therapy. Newly, there has also been a significant improvement in the available technologies (e.g., catheters and pumps) of IDDDs. The use of good clinical practice and the adherence to guidelines together with continuous improvement and clinical research are crucial for the success of this therapy.

\section{Acknowledgments}

Funding: This work was supported by Fondazione per l'Oncologia Pediatrica.

\section{Footnote}

Provenance and Peer Review: This article was commissioned by the Guest Editor (Dr. Antonio Ruggiero) for the series "Pain Therapy" published in Annals of Translational Medicine. The article was sent for external peer review organized by the Guest Editor and the editorial office.

Reporting Checklist: The authors have completed the Narrative Review reporting checklist. Available at http:// dx.doi.org/10.21037/atm-20-3814

Conflicts of Interest: All authors have completed the ICMJE uniform disclosure form (available at http://dx.doi. org/10.21037/atm-20-3814). The series "Pain Therapy" was commissioned by the editorial office without any funding or sponsorship. AR served as the unpaid Guest Editor of the series and serves as an unpaid editorial board member of Annals of Translational Medicine from Nov 2019 to Oct 2021. The other authors have no other conflicts of interest to declare.

Ethical Statement: The authors are accountable for all aspects of the work in ensuring that questions related to the accuracy or integrity of any part of the work are appropriately investigated and resolved.

Open Access Statement: This is an Open Access article distributed in accordance with the Creative Commons Attribution-NonCommercial-NoDerivs 4.0 International License (CC BY-NC-ND 4.0), which permits the noncommercial replication and distribution of the article with the strict proviso that no changes or edits are made and the original work is properly cited (including links to both the formal publication through the relevant DOI and the license). 
See: https://creativecommons.org/licenses/by-nc-nd/4.0/.

\section{References}

1. Deer TR, Caraway DL, Wallace MS. A definition of refractory pain to help determine suitability for device implantation. Neuromodulation 2014;17:711-5.

2. Deer TR, Pope JE, Hayek SM, et al. The Polyanalgesic Consensus Conference (PACC): Recommendations on Intrathecal Drug Infusion Systems Best Practices and Guidelines. Neuromodulation 2017;20:96-132. Erratum in: Neuromodulation. 2017 Jun;20(4):405-406. doi: 10.1111/ner.12618.

3. Kim D, Sidov A, Mandhare V, et al. Role of pretrial systemic opioid requirements intrathecal trial dose and non-psychological factors as predictors of outcome of intrathecal pump therapy: one clinician's experience with lumbar postlaminectomy pain. Neuromodulation 2011;14:165-75.

4. Duarte RV, Raphael JH, Sparkes E, et al. Long-term intrathecal drug administration for chronic nonmalignant pain. J Neurosurg Anesthesiol 2012;24:63-70.

5. Jain S, Malinowski M, Chopra P, et al. Intrathecal drug delivery for pain management: recent advances and future developments. Expert Opin Drug Deliv 2019;16:815-22.

6. Hayes C, Jordan MS, Hodson FJ, et al. Ceasing intrathecal therapy in chronic non-cancer pain: an invitation to shift from biomedical focus to active management. PLoS One 2012;7:e49124.

7. Attinà $\mathrm{G}$, Ruggiero $\mathrm{A}$, Maurizi $\mathrm{P}$, et al. Transdermal buprenorphine in children with cancer-related pain. Pediatr Blood Cancer 2009;52:125-7.

8. van den Beuken-van Everdingen MH, de Rijke JM, Kessels AG, et al. Prevalence of pain in patients with cancer: a systematic review of the past 40 years. Ann Oncol 2007;18:1437-49.

9. Carvajal G, Dupoiron D, Seegers V, et al. Intrathecal Drug Delivery Systems for Refractory Pancreatic Cancer Pain: Observational Follow-up Study Over an 11-Year Period in a Comprehensive Cancer Center. Anesth Analg 2018;126:2038-46.

10. Fishbain DA, Cutler R, Rosomoff HL, et al. Chronic pain-associated depression: antecedent or consequence of chronic pain? A review. Clin J Pain 1997;13:116-37.

11. Brown J, Klapow J, Doleys D, et al. Disease-specific and generic health outcomes: a model for the evaluation of long-term intrathecal opioid therapy in noncancer low back pain patients. Clin J Pain 1999;15:122-31.
12. Monsalve V, de Andres JA, Valia JC. Application of a psychological decision algorithm for the selection of patients susceptible to implantation of neuromodulation systems for the treatment of chronic pain. A proposal. Neuromodulation 2000;3:191-200.

13. Pardridge WM. Blood-brain barrier drug targeting: the future of brain drug development. Mol Interv 2003;3:90-105, 51.

14. Triarico S, Maurizi P, Mastrangelo S, et al. Improving the Brain Delivery of Chemotherapeutic Drugs in Childhood Brain Tumors. Cancers (Basel) 2019;11:824.

15. Bernards CM. Recent insights into the pharmacokinetics of spinal opioids and the relevance to opioid selection. Curr Opin Anaesthesiol 2004;17:441-7.

16. Inturrisi CE. Clinical pharmacology of opioids for pain. Clin J Pain 2002;18:S3-13.

17. Michael A, Buffen E, Rauck R, el al. An in vivo canine study to assess granulomatous responses in the MedStream Programmable Infusion System (TM) and the SynchroMed II Infusion System®. Pain Med 2012;13:175-84.

18. Kumar P, Sunkaraneni S, Sirohi S, et al. Hydromorphone efficacy and treatment protocol impact on tolerance and mu-opioid receptor regulation. Eur J Pharmacol 2008;597:39-45.

19. Johansen MJ, Satterfield WC, Baze WB, et al. Continuous intrathecal infusion of hydromorphone: safety in the sheep model and clinical implications. Pain Med 2004;5:14-25.

20. Allen JW, Horais KA, Tozier NA, et al. Opiate pharmacology of intrathecal granulomas. Anesthesiology 2006;105:590-8.

21. Yaksh TL, Steinauer JJ, Veesart SL, et al. Alfentanil: correlations between absence of effect upon subcutaneous mast cells and absence of granuloma formation after intrathecal infusion in the dog. Neuromodulation 2013;16:459-66.

22. Triarico S, Capozza MA, Mastrangelo S, et al. Intranasal therapy with opioids for children and adolescents with cancer: results from clinical studies. Support Care Cancer 2019;27:3639-45.

23. Colpaert FC, Leysen JE, Michiels M, et al. Epidural and intravenous sufentanil in the rat: analgesia, opiate receptor binding, and drug concentrations in plasma and brain. Anesthesiology 1986;65:41-9.

24. Yaksh TL, Tozier N, Horais KA, et al. Toxicology profile of N-methyl-D-aspartate antagonists delivered by intrathecal infusion in the canine model. Anesthesiology 2008;108:938-49.

25. Mironer YE, Tollison CD. Methadone in the intrathecal treatment of chronic nonmalignant pain resistant to other 
neuroaxial agents: the first experience. Neuromodulation 2001;4:25-31.

26. Zamponi GW, Striessnig J, Koschak A, et al. The physiology, pathology, and pharmacology of voltage-gated calcium channels and their future therapeutic potential. Pharmacol Rev 2015;67:821-70.

27. Takasusuki T, Yaksh TL. Regulation of spinal substance p release by intrathecal calcium channel blockade. Anesthesiology 2011;115:153-64.

28. Alicino I, Giglio M, Manca F, et al. Intrathecal combination of ziconotide and morphine for refractory cancer pain: a rapidly acting and effective choice. Pain 2012;153:245-9.

29. Dupoiron D, Bore F, Lefebvre-Kuntz D, et al. Ziconotide adverse events in patients with cancer pain: a multicenter observational study of a slow titration, multidrug protocol. Pain Physician 2012;15:395-403.

30. Deer TR, Pope JE, Hanes MC, et al. Intrathecal Therapy for Chronic Pain: A Review of Morphine and Ziconotide as Firstline Options. Pain Med 2019;20:784-98.

31. Horazeck C, Huh AS, Huh BK. Acute rhabdomyolysis in a patient with long-term exposure to intrathecal ziconotide: a case report. Pain Pract 2015;15:E34-9.

32. Rainov NG, Heidecke V, Burkert W. Long-term intrathecal infusion of drug combinations for chronic back and leg pain. J Pain Symptom Manage 2001;22:862-71.

33. Hayek SM, Veizi E, Hanes M. Intrathecal Hydromorphone and Bupivacaine Combination Therapy for Post-Laminectomy Syndrome Optimized with PatientActivated Bolus Device. Pain Med 2016;17:561-71.

34. Bernards CM. Cerebrospinal fluid and spinal cord distribution of baclofen and bupivacaine during slow intrathecal infusion in pigs. Anesthesiology 2006;105:169-78.

35. Covino BG. Pharmacology of local anaesthetic agents. Br J Anaesth 1986;58:701-16.

36. McRoberts WP, Apostol C, Haleem A. Intrathecal Bupivacaine Monotherapy with a Retrograde Catheter for the Management of Complex Regional Pain Syndrome of the Lower Extremity. Pain Physician 2016;19:E1087-92.

37. Rauck RL, North J, Eisenach JC. Intrathecal clonidine and adenosine: effects on pain and sensory processing in patients with chronic regional pain syndrome. Pain 2015;156:88-95.

38. Engelman E, Marsala C. Efficacy of adding clonidine to intrathecal morphine in acute postoperative pain: metaanalysis. Br J Anaesth 2013;110:21-7.

39. Wong CS, Liaw WJ, Tung CS, et al. Ketamine potentiates analgesic effect of morphine in postoperative epidural pain control. Reg Anesth 1996;21:534-41.

40. Fisher K, Coderre TJ, Hagen NA. Targeting the Nmethyl$\mathrm{D}$-aspartate receptor for chronic pain management. Preclinical animal studies, recent clinical experience and future research directions. J Pain Symptom Manage 2000;20:358-73.

41. Stotz M, Oehen HP, Gerber H. Histological findings after long-term infusion of intrathecal ketamine for chronic pain: a case report. J Pain Symptom Manage 1999;18:223-8.

42. Karpinski N, Dunn J, Hansen L, et al. Subpial vacuolar myelopathy after intrathecal ketamine: report of a case. Pain 1997;73:103-5.

43. Turner JA, Sears JM, Loeser JD. Programmable intrathecal opioid delivery systems for chronic noncancer pain: a systematic review of effectiveness and complications. Clin J Pain 2007;23:180-95.

44. Hustak EC, Engle MP, Viswanathan A, et al. Lumbar subarachnoid hematoma following an epidural blood patch for meningeal puncture headache related to the implantation of an intrathecal drug delivery system. Pain Physician 2014;17:E405-11.

45. Stearns LM, Abd-Elsayed A, Perruchoud C, et al. Intrathecal Drug Delivery Systems for Cancer Pain: An Analysis of a Prospective, Multicenter Product Surveillance Registry. Anesth Analg 2020;130:289-97.

46. Paice JA, Penn RD, Shott S. Intraspinal morphine for chronic pain: a retrospective, multicenter study. J Pain Symptom Manage 1996;11:71-80.

47. Knight KH, Brand FM, Mchaourab AS, et al. Implantable intrathecal pumps for chronic pain: highlights and updates. Croat Med J 2007;48:22-34.

48. Freeman ED, Hoelzer BC, Eldrige JS, et al. Fibrin glue to treat spinal fluid leaks associated with intrathecal drug systems. Pain Pract 2014;14:570-6.

49. Sood A, Kotamarti VS, Therattil PJ et al. Sclerotherapy for the Management of Seromas: A Systematic Review. Eplasty 2017;17:e25.

50. Bottros MM, Christo PJ. Current perspectives on intrathecal drug delivery. J Pain Res 2014;7:615-26.

51. Dahan A, Aarts L, Smith TW. Incidence, Reversal, and Prevention of Opioid-induced Respiratory Depression. Anesthesiology 2010;112:226-38.

52. Chinachoti T, Nilrat P, Samarnpiboonphol P. Nausea, vomiting and pruritus induced by intrathecal morphine. J Med Assoc Thai 2013;96:589-94.

53. Kuipers PW, Kamphuis ET, van Venrooij GE, et al. Intrathecal opioids and lower urinary tract function: a urodynamic evaluation. Anesthesiology 2004;100:1497-503. 
54. Naumann C, Erdine S, Koulousakis A, et al. Drug adverse events and system complications of intrathecal opioid delivery for pain: origins, detection, manifestations, and management. Neuromodulation 1999;2:92-107.

55. Gudin JA, Laitman A, Nalamachu S. Opioid Related Endocrinopathy. Pain Med 2015;16 Suppl 1:S9-15.

56. Hoederath P, Gautschi OP, Land M, et al. Formation of two consecutive intrathecal catheter tip granulomas within nine months. Cent Eur Neurosurg 2010;71:39-42.

57. Jourdain V, Cantin L, Prud'homme M, et al. Intrathecal morphine therapy-related granulomas: faster to grow than thought. Neuromodulation 2009;12:164-8.

58. Leong SK, Laing B, Saines N. Magnetic resonance imaging (MRI) and computed tomography (CT) fndings in intrathecal catheter granuloma: report of two cases. Eur J Radiol Extra 2010;74:e17-21.

59. Medtronic Neuromodulation: intrathecal distal end catheter occlusions as a result of $\mathrm{pH} \&$ salt concentration gradients between delivery solution and cerebrospinal fluid (CSF). Available online: http://professional.medtronic. com/wcm/groups/mdtcom_sg/@mdt/@neuro/documents/ documents/inflammatory_mass_letter.pdf

60. Allen JW, Horais KA, Tozier NA, et al. Time course and role of morphine dose and concentration in intrathecal granuloma formation in dogs: a combined magnetic resonance imaging and histopathology investigation. Anesthesiology 2006;105:581-9.

Cite this article as: Capozza MA, Triarico S, Mastrangelo S, Attinà G, Maurizi P, Ruggiero A. Narrative review of intrathecal drug delivery (IDD): indications, devices and potential complications. Ann Transl Med 2021;9(2):186. doi: 10.21037/ atm-20-3814
61. Deer TR, Prager J, Levy R, et al. Polyanalgesic Consensus Conference--2012: consensus on diagnosis, detection, and treatment of catheter-tip granulomas (inflammatory masses). Neuromodulation 2012;15:483-95; discussion 496.

62. Lad SP, Li G, Lin SC, et al. Intracranial hypotension from intrathecal baclofen pump insertion. A case report and review of the literature. Stereotact Funct Neurosurg 2008;86:75-9.

63. De Andres J, Esparza MJ, Ferrer-Rebolleda J, et al. Radioisotope cisternography: a potentially useful tool for headache diagnosis in patients with an IDD pump. Pain Physician 2014;17:E89-94.

64. Wilkes D. Programmable intrathecal pumps for the management of chronic pain: recommendations for improved efficiency. J Pain Res 2014;7:571-7.

65. Pope J, Deer T. Intrathecal drug delivery: available technologies. In: Treatment of chronic pain conditions: a comprehensive handbook. New York (NY): Springer, 2018:91-192.

66. Rosenow JM. Surgical techniques for intrathecal medication delivery system implantation. In: Krames ES, Peckham PH, Rezai AR. editors. Neuromodulation. London: Elsevier, 2009:1027-32.

67. Bolash R, Mekhail N. Intrathecal pain pumps: indications, patient selection, techniques, and outcomes. Neurosurg Clin N Am 2014;25:735-42. 